\title{
Inflammatory odontogenic cyst on an osseointegrated implant: A peri-implant cyst? New entity proposed
}

\section{Zapalna torbiel zębopochodna przy osteointegrowanym implancie - torbiel okołowszczepowa? Propozycja nowego rozpoznania}

\author{
Nabil Kochaji \\ Al-Sham Private University, Faculty of Dentistry, Damascus University, Syria \\ A - research concept and design; $\mathrm{B}$ - collection and/or assembly of data; $\mathrm{C}$ - data analysis and interpretation; \\ $D$ - writing the article; $E$ - critical revision of the article; $F$ - final approval of article
}

Address for correspondence

Nabil Kochaji

E-mail: oralpathology@gmail.com

Funding sources

none declared

Conflict of interest

none declared

Acknowledgements

Special thanks to prof. dr. Edward Odell, who has made the completion of this paper possible.

Received on April 04, 2017

Revised on June 15, 2017

Accepted on June 29, 2017

\begin{abstract}
Peri-implant lesion, an inflammation around the distal portion of an implant, is one of the main reasons for implant failure. It is considered as the equivalent of a periapical granuloma. Theoretically, an inflammatory cyst analogous to a radicular cyst could develop in a peri-implant lesion but this does not appear to have been reported in the literature. Although peri-implantitis and peri-implant lesion are now scientifically accepted as implant failure causes, an inflammatory odontogenic peri-implant cyst that develops from periimplant granuloma has never been reported previously.

Two cases of a peri-implant cyst are reported in this article. Both developed around the apical portion of an implant placed into an area without any preexisting dental infection, periapical granuloma or cyst. Radiographically, they had typical features of a radicular cyst and on pathological examination were lined by a variably hyperplastic non-keratinized epithelium. The name "peri-implant cyst" is proposed for this new entity.
\end{abstract}

Key words: implant, odontogenic cyst, peri-implant cyst

Słowa kluczowe: implant, torbiel zębopochodna, torbiel okołowszczepowa

DOI

$10.17219 / \mathrm{dmp} / 75571$

Copyright

(-) 2017 by Wroclaw Medical University

and Polish Dental Society

This is an article distributed under the terms of the

Creative Commons Attribution Non-Commercial License

(http://creativecommons.org/licenses/by-nc-nd/4.0/) 
Shortly after the introduction of the osseointegrated implant, it became apparent that the tissue surrounding implants could suffer from diseases of the same type as affect the periodontal tissues. Peri-implantitis was recognized in $1963^{1}$ and named following discussion of appropriate terminology in the literature and subsequently shown to be "...a site specific infection which yields many features in common with chronic periodontitis",2,3

Subsequently, with larger numbers of implants having been inserted, additional types of implant-associated lesions became apparent. The implant periapical lesion is considered the equivalent of a periapical granuloma and is presumed to arise through persistence of pre-existing periapical inflammation, though similar lesions might arise from surgical trauma ${ }^{4}$ or a foreign-body reaction, for example to starch particles. ${ }^{5}$

Implant periapical lesions have been reported to have a prevalence of $0.26 \%$ of implants placed ${ }^{6}$ and are found usually around long implants placed in dense bone..$^{7-11}$ Their pathogenesis has been proposed to be multifactorial and remains unclear., ${ }^{72}$

The radicular cyst is a well known complication of periapical granulomas on teeth, caused by proliferation of epithelium of the cell rests of Malassez. As these cell rests can persist following extraction, there is no reason why the equivalent of a radicular cyst could not form on an implant, though this appears unreported.

This article describes 2 patients with peri-implant lesions that were found to have a central cyst cavity and an epithelial cyst lining on histological examination. The term peri-implant cyst is suggested for these odontogenic cysts, which are thought to be the implant-associated equivalent of radicular cysts.

\section{Case reports}

\section{Case 1}

A 45-year-old female, non-smoker and non-alcohol user with good oral hygiene presented to her dentist requesting implant placement in the edentulous right mandible posterior to the premolars (Fig. 1, left). The implant site was prepared using the system kit using a hand piece with external irrigation. After drilling the socket, the implant $(4.9 \times 12 \mathrm{~mm}$, cylinder) was placed using the ratchet with normal torque about $20 \mathrm{~N} / \mathrm{cm}$ for primary stability. On review 6 months later, the implant appeared successful, with complete osseointegration, a healed mucosal interface and no signs of failure. However, a radiograph revealed the presence of a peri-implant apical radiolucency $7 \mathrm{~mm}$ in maximum diameter (Fig. 1, center). No alveolar expansion or sinus were present. The implant was removed and the apical lesion submitted for histological evaluation (Fig. 1, right). Two additional implants placed in the contralateral edentulous mandible integrated normally.

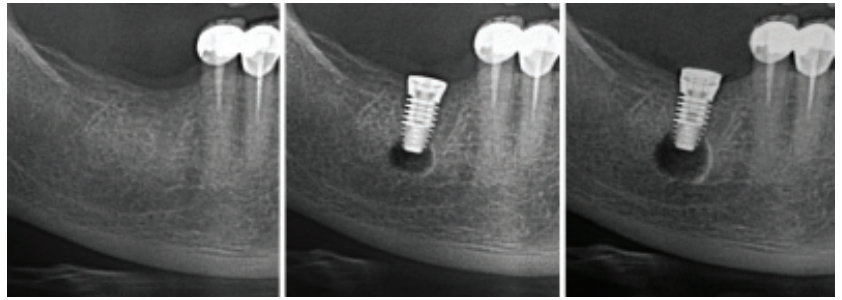

Fig. 1. Radiographs of case 1: left, preoperative. The faint outlines of the lamina dura of the extracted teeth is visible and there is complete healing of medullary and cortical bone. No radiolucency is present. Center, 6 months after implant placement, an apical corticated radiolucency with a smooth outline is present. Right, 9 months after implant placement, the radiolucency has persisted and appears to have enlarged slightly, though the 2 films are not standardized views

Macroscopically, the lesion was cystic and microscopically the lumen was lined by a layer of inconspicuous nonkeratinized stratified squamous epithelium lying on an inflamed fibrous tissue wall with a dense capsule-like outer

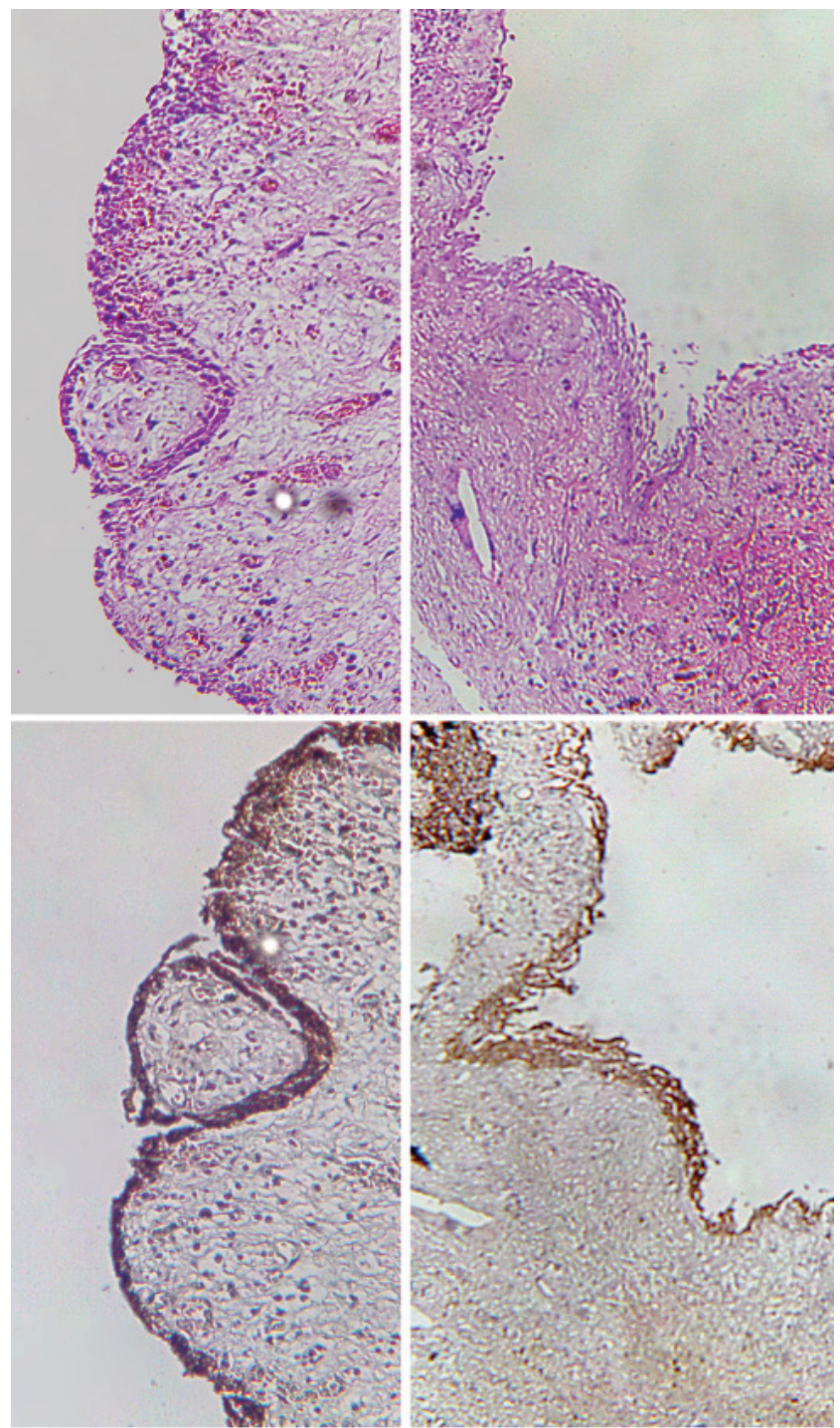

Fig. 2. Histological view of case 1: H\&E (above) and PanCK (below) of case no. 1. The epithelial lining of the cyst lumen is visible in routine H\&E stain and highlighted by keratin immunohistochemistry. There is light inflammatory reaction in the underlying connective tissue 
layer (Fig. 2, above). The epithelial nature of the lining cells was confirmed with pan-cytokeratin immunohistochemistry, performed on paraffin embedded samples using routine methods with diaminobenzidine visualization and anti-cytokeratin antibody PAN-CK; MA5-13203 (Fig. 2 , below). The histological appearances were identical to those of a radicular or apical inflammatory dental cyst around the apex of a tooth.

\section{Case 2}

A 21-year-old female non-smoker and non-alcohol user with moderate oral hygiene was referred to her dentist asking for implant placement in the edentulous area posterior to her lower right first molar (Fig. 3, left). The site was prepared using a hand piece with external irrigation and then an implant $(4.9 \times 10 \mathrm{~mm}$, cylinder $)$ was placed using the ratchet, with normal torque about $30 \mathrm{~N} / \mathrm{cm}$ for primary stability (Fig. 3, center).

The implant on the right was assessed 9 months after placement. Clinically the wound was completely healed and no signs of failure were present. However, radiographic evaluation revealed the presence of a peri-implant apical radiolucency of greatest dimension $14 \mathrm{~mm}$ (Fig. 3, right). No alveolar expansion or sinus were present.

The implant was removed and the apical lesion was submitted for histological evaluation. Microscopically the lesion consisted of a cyst wall with the lumen lined by hyperplastic non-keratinized epithelium of several cell layers thickness supported by immature and mature fibrous tissue (Fig. 4, above). On pan-cytokeratin staining using the same methods as in case 1, the cyst lining layer was confirmed as epithelium (Fig. 4, below) and the histological appearances were indistinguishable from a radicular cyst.

\section{Discussion}

Peri-implant lesions have been ascribed to a variety of causes $^{4-12}$ including bone overheating, absence of primary implant stability, reduced healing ability of the host, implant overloading, contamination during production or insertion, pre-existing bone infections, residual root particles and foreign bodies, placement of an implant into an infected maxillary sinus or the possibility of persisting periapical infection from a tooth at the implant site.

However, most of these causes are theoretical and those based on theories of persistent infection seem an unlikely cause as the nidus of infection has been eliminated. Periapical granulomas on teeth are not infected, but maintained by leakage of bacteria, bacterial and host autolytic products from the root canal. Endodontic treatment or removal of the tooth would normally allow healing, regardless of implant placement, unless rare extraradicular infection were present or an implant biofilm developed.

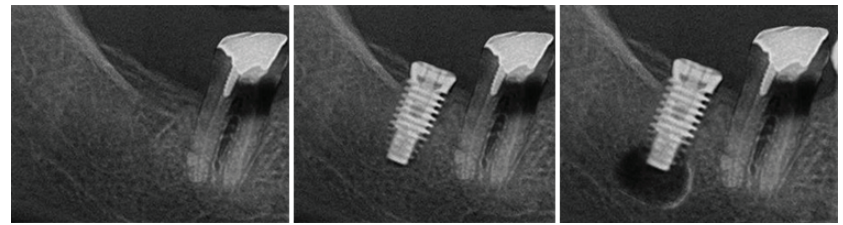

Fig. 3. Radiographs of case 2: left, preoperative. No radiolucency is present. Center, directly after implant insertion, primary osteointegration is visible. Right, 9 months after implant placement, a radiolucency has developed to the apex of the implant

Radicular cyst is a well recognized consequence of periapical granuloma and the conditions that allow cyst formation would appear to be present in a peri-implant lesion. Critical to cyst formation is the presence of cell rests of Malassez. ${ }^{13}$ These odontogenic epithelial cells are remnants of Hertwig's root sheath, formed from both inner and outer enamel epithelium after crown formation. ${ }^{13-15}$

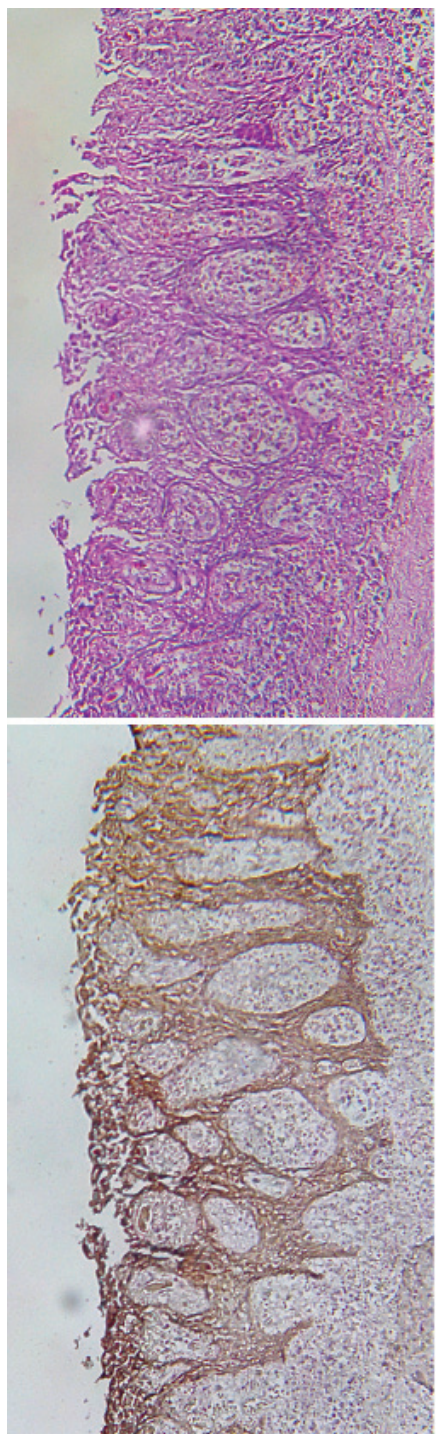

Fig. 4. Histological view of case 2: H\&E (above) and PanCK (below) of case 2 cystic lesion lined by non-keratinized epithelium with a more prominent inflammatory infiltrate and hyperplastic arcading non-keratinized epithelium. Original magnification $\times 40$ 
Under normal conditions, rests of Malassez cells remain inconspicuous as a meshwork around the root, especially in the apical area ${ }^{13}$ where they may play a role in preventing ankylosis. During tooth extraction, the periodontal ligament is disrupted but rests of Malassez cells persist ${ }^{14}$ and may be found in edentulous alveolar bone many years after tooth removal.

Persistent inflammation around the apex of a tooth in a periapical granuloma may lead in up to $10 \%$ of untreated cases to the formation of a radicular cyst ${ }^{16}$. Inflammation stimulates proliferation of the rests of Malassez and the epithelium forms the lining of the radicular cyst. ${ }^{16,17}$

Peri-implant lesions, as noted earlier, tend to affect long implants in dense bone, so that any persisting inflammatory lesion is likely to be in the region where rests of Malassez would persist, because rests are more frequent around the apical third of the root. It is also possible that the additional surgical trauma and force required to place long implants may itself contribute to the formation of peri-implant lesions. It would also seem likely that the risk of developing an inflammatory cyst on an implant would be lower than on a tooth because the close anatomic relationship of the epithelial rests to the apex has been lost. Persistence of rests of Malassez in a peri-implant lesion has been shown in the literature ${ }^{11}$ though the authors of that paper did not comment specifically on the cluster of epithelial cells shown in their published figure.

An alternative source of epithelium that might form a cyst lining on an implant includes surgically implanted cells. However, displaced mucosal cells normally lose their proliferation capacity in a new environment ${ }^{18}$ and undergo apoptosis when separated from their connective tissue. An alternative source might be a sinus lining, with in-growth of epithelium from the surface. ${ }^{19}$ However, in the current cases, no sinus was present on either implant.

The histological appearances of the cysts in these patients is completely compatible with radicular cyst. There was variable inflammation, an occasional cholesterol cleft, a mixed chronic inflammatory infiltrate and a lining of non-keratinizing epithelium. These features are not in themselves diagnostic and the key diagnostic feature of radicular cyst is its site on the apex of a non-vital tooth. Vitality is not a useful criterion for an implant, ${ }^{20}$ but the location at the level of the apices of preexisting teeth would be sufficiently specific to make the diagnosis of peri-implant cyst. Such cysts should be removed and subjected to histological examination, although they appear excessively rare.

In conclusion, peri-implant lesions are well recognized and there is no biological reason why an odontogenic cyst should not arise in them. It is proposed that an inflammatory odontogenic cyst associated with an implant does develop on rare occasions, but that the risk must be very low. Peri-implant cyst is proposed as a name for this entity.

\section{References}

1. Boucher CO, ed. Current Clinical Dental Terminology; A Glossary of Accepted terms in All Disciplines of Dentistry $1^{\text {st }}$ ed. St. Louis, Mo: Mosby; 1963.

2. Mombelli A, van Oosten MA, Schurch EJr. The microbiota associated with successful or failing osteointegrated titanium implants. Oral Microbiol Immunol. 1987;2:145-151.

3. Albrektsson T, Isidor F. Consensus report of session IV. In: Lang, N.P. \& Karring, T., eds. Proceedings of the $1^{\text {st }}$ European Workshop on Periodontology. Berlin: Quintessence; 1994:365-369.

4. Oh Tae-Ju, Yoon Joongkyo, Wang Hom-Lay. Management of the implant periapical lesion: A case report. Implantdent. 2003;12:41-46.

5. Nedir R, Bischof M, Pujol O. Starch-induced implant periapical lesion: A case report. Int J Oral Maxillofac Implants, 2007;22:1001-1006.

6. Berglundh T, Persson L, Klinge B. A systematic review of the incidence of biological and technical complications in implant dentistry reported in prospective longitudinal studies of at least 5 years. J Clin Periodontol. 2002;29:197-212.

7. Esposito M, Hirsch J, Lekholm U, Thomsen P. Differential diagnosis and treatment strategies for biologic complications and failing oral implants: A review of the literature. Int J Oral Maxillofac Implants, 1999;14:473-490.

8. Reiser GM, Nevins M. The implant periapical lesion: Etiology, prevention and treatment. Compendium, 1995;16:768-777.

9. Piattelli A, Scarano M, Piattelli M. Abscess formation around the apex of a maxillary root form implant: Clinical and microscopical aspects. A case report. J Periodontol. 1995;66:899-903.

10. Piattelli A, Scarano A, Balleri P, et al. Clinical and histological evaluation of an active "implant periapical lesion". A case report. Int J Oral Maxillofac Implants, 1998;13:713-716.

11. Piattelli A, Scarano A, Piattelli M, et al. "Implant periapical lesion". Clinical, histological and histochemical aspects. A case report. Int J Periodont Res Dent. 1998;18:181-187.

12. Tolga FT, Cenk E, Isil S. Treatment of periapical dental implant pathology with guided bone regeneration. Turk J Med Sci. 2006;36:191-196.

13. Xiaofeng HA, Pablo B, Harold C., et al. Fate of HERS during tooth root development. Dev Biol. 2009;334:22-30.

14. Struys T, Schuermans J, Corpas L, et al. Proliferation of epithelial rests of Malassez following auto-transplantation of third molars: A case report. J Med Case Rep. 2010;4:328.

15. Andujar MB, Magloire H, Hartmann DJ, et al. Early mouse molar root development: cellular changes and distribution of fibronectin, laminin and type-IV collagen. Differentiation, 1985;30:111-122.

16. Vernal R, Dezerega A, Dutzan N, et al. ANKL in human periapical granuloma: possible involvement in periapical bone destruction. Oral Dis. 2006;12:283-289.

17. García CC, Diago MP, Mira BG, et al. Expression of cytokeratins in epithelialized periapical lesions. Oral Surg Oral Med Oral Pathol Oral Radiol Endod. 2009;107:e43-46.

18. Frisch SM, Screaton RA. Anoikis mechanisms. Curr Opin Cell Biol. 2001;13:555-562.

19. Temmerman A, Lefever D, Teughles W, et al. Etiology and treatment of periapical lesions around dental implants. Periodontol. 2000. 2014;66:247-254.

20. Poli P, Cicciu M, Beretta M, et al. Peri-implant mucositis and periimplantitis: A current understanding of their diagnosis, clinical implications, and a report of treatment using a combined therapy approach. J Oral Implantol. 2017:43:45-50. 